\title{
EVALUACIÓN DE LA REDUCCIÓN DE Pb++EN HIERRO FUNDIDO EN SOLUCIÓN ÁCIDA ${ }^{33}$
}

\author{
Guerreros Meza, Manuel134, Muedas Castañeda, Rubén² \\ Facultad de Ingeniería Metalúrgica y de Materiales de la Universidad Nacional del Centro del Perú
}

\begin{abstract}
RESUMEN
La recuperación de plomo de la galena por medio de lixiviación es compleja, principalmente porque la disolución tiene una cinética muy lenta en la mayoría de los medios de lixiviación y produce gas de cloro en la etapa de reducción. En contraste, la cementación con hierro fundido para producir plomo es un proceso muy atractivo debido a que tiene una cinética rápida y es un proceso selectivo en medio cloruro. En la Investigación se estudia la reducción de plomo en hierro fundido en una celda electroquímica utilizando electrodos de hierro fundido. Para ello se estudia el procedimiento de los electrodos durante la reducción del plomo. El objetivo es analizar el mecanismo de la reacción de las partículas de hierro fundido empleando los fundamentos de la cinética electroquímica en base a las reacciones anódicas y catódicas que ocasionan diferencias de potenciales en la superficie y a partir de los resultados obtenidos, analizar la reducción del plomo en medio acuoso.
\end{abstract}

Palabras claves: Mena, lixiviación, concentrado, cementación, hidrometalúrgia, pirometalúrgia.

\section{ASSESSMENT OF THE REDUCTION OF Pb++ IN CAST IRON IN ACID SOLUTION}

\begin{abstract}
The recovery of lead from galena by leaching is complex, primarily because the dissolution kinetics is very slow in most of the means of leaching and chlorine gas produced in the reduction stage. In contrast, cementation with iron to produce lead is a very attractive because it has fast kinetics and is a selective process in the middle chloride. Research In studying the reduction of lead in castiron in an electrochemical cell using iron electrodes. We studied the procedure of the electrodes during the reduction of lead. The objective is to analyze the mechanism of the reaction of iron particles using the fundamentals of electrochemical kinetics based on the anodic and cathodic reactions that cause potential differences in the surface and from the results, analyze the reduction of lead in aqueous media.
\end{abstract}

Key words: Mena, leaching, concentrated, cementing, hydrometallurgy pyrometallurgy.

33 Trabajo de investigación fue recibido el 07/05/2010 retornado para su revisión el 15/06/2010 y aprobado para su publicación 16/11/2010.

34 manuelguerreros@yahoo.com 


\section{INTRODUCCIÓN}

Los procesos tradicionales de obtención de los metales si bien son eficientes contaminan con emisiones gaseosas de bióxido de azufre. La necesidad de minimizar la contaminación ha impulsado el desarrollo de procesos emergentes de lixiviación y cementación que muestran las mejores expectativas de aplicación industrial.

La disolución de minerales sulfurados de plomo en soluciones de ácido clorhídrico han sido desarrollados por Sherman and Strickland en EE.UU. ${ }^{1}$ con el inconveniente de que estos originan la emanación de los gases tóxicos de cloro y sulfuro de hidrogeno.

Trabajos de investigación de la recuperación de plomo de concentrados empleando tostación clorurante y lixiviación con cloruro de sodio también han sido desarrollados por Tolley y Stauter.(3) Por otro lado Andersen y Boe nos señala que: "Han estudiado la lixiviación oxidante y clorurante de concentrados de sulfuros complejos".

También Morizot y Winter ${ }^{35}$ (Departamento Mineralúrgic, Bureau de Recherches, Geologiques et Minieres), nos señalan que: "Han desarrollado un proceso hidrometalúrgico empleando la volatilización y cloruración con cloruro de calcio de concentrados de minerales complejos"

Concluiré que la recuperación de plomo de concentrados de galena es el proceso de lixiviación del concentrado con cloruro férrico y cloruro de sodio a $95^{\circ} \mathrm{C}$.

Luego el plomo es extraído como cloruro y finalmente la reducción a plomo metal $(7,8)$.

En este artículo se muestran datos de la investigación electroquímica de la reducción del plomo en hierro fundido como alternativa de obtención de plomo por la vía hidrometalúrgica.

\section{MATERIALES Y MÉTODOS}

La metodología es experimental en su primera parte, cuya planificación se va mostrando a continuación y luego de las pruebas de laboratorio, la presentación y discusión de los resultados.

\section{a) FABRICACIÓN DE LOS ELECTRODOS DE TRABAJO}

Los electrodos de trabajo se fabricaron de diferentes metales: Acero, Hierro fundido.

\section{b) PREPARACIÓN DE LAS SOLUCIONES ELECTROLITO}

De acuerdo a los estándares ASTM se tienen que correr las pruebas potenciostáticas en una celda especial de 1 litro. Para efectos de esta investigación se han corrido pruebas para cada electrodo con las siguientes características:

- Análisis del efecto de la acidez

- Análisis del efecto de la acidez y la presencia del ión férrico

- Análisis del efecto de los lones $\mathrm{Pb}++$

- Efecto de la concentración de la solución Los reactivos químicos empleados para preparar el electrolito: cloruro de plomo, ácido clorhídrico p.a. y agua destilada como solvente.

\section{MÉTODO}

Las pruebas electroquímicas se realizaron en un sistema de investigación electroquímico compuesto por: un Potenciostato/ Galvanostato, celda electroquímica y, Software Electroquímico instalado a una computadora. El potenciostato, trabaja con un sistema de tres electrodos: electrodo de trabajo constituido por la muestra a analizar, electrodo de referencia y electrodo auxiliar a través del cual fluye la corriente cerrando el circuito.

Se utilizó un Potenciostato/ Galvanostato modelo PGP201 de 20V/10A, que trae incorporado un sistema de adquisición de datos (Software Electroquímico VoltaMaster)

\section{RESULTADOS}

Los resultados de las pruebas experimentales son mostrados en la figura 1 :

\section{Material:}


DISCU

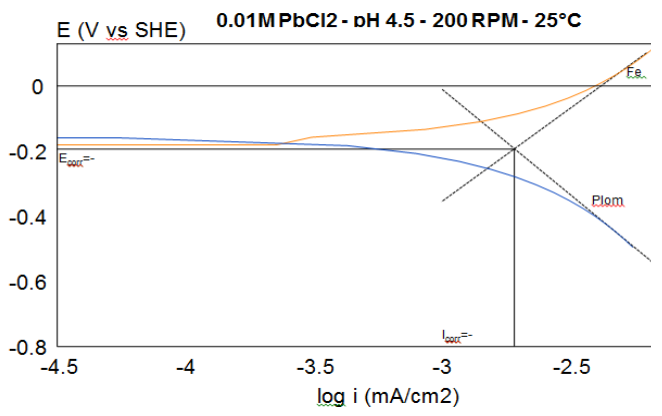

Figura No1- Potencial Mixto - Sistema Plomo Fierro Fundido

\section{DISCUSIÓN}

En el trabajo de investigación, se realiza la correlación de los datos que se han obtenido experimentalmente, con modelos cinéticos aplicados a sistemas electroquímicos, en las condiciones que se indican. De los datos obtenidos a partir de las curvas de polarización, potenciales de circuito abierto y los potenciales mixtos de cementación de plomo se determinó por vía electroquímica el modelo cinético del comportamiento anódico del hierro fundido evaluando el efecto del $\mathrm{pH}$, de la concentración del plomo, de la temperatura y de la velocidad de agitación. Se obtuvo una energía de activación de $\mathbb{E}$ a $=18.8 \mathrm{Kj} / \mathrm{mol}$. para la cementación del plomo con el SAE 1020. El modelo semi-empírico encontrado:

$i_{0}=2.8112 \mathrm{E}+07 *\left(\frac{1}{p H}\right)^{1.3004} *\left[\mathrm{PbCl}_{2}\right]^{1.0104 *} \exp \left(\frac{-2355.3385}{T}\right)$

De acuerdo a este modelo las mejores condiciones operativas para la cementación son un $\mathrm{pH}=1.5$, velocidad de agitación de $200 \mathrm{rpm}$, temperatura de $90^{\circ} \mathrm{C}$ y concentración de cloruro de plomo de 0,05 M.

\section{CONCLUSIONES}

La recuperación del plomo de soluciones cloruradas en la cementación es un proceso electroquímico en el cual un metal más noble, que se encuentra en forma iónica en solución desplaza de su estado de equilibrio sólido a un metal menos noble que se pone en contacto con dicha solución con las siguientes conclusiones:

1. La mayor solubilidad de los cloruros respecto a los sulfatos permiten obtener soluciones más concentradas

2. Mejor cinética de disolución del plomo
3. Existe la posibilidad de obtener plomo al estado elemental

4. La ventaja de reducción de un solo electrón

\section{REFERENCIAS BIBLIOGRÁFICAS}

- Andersen E., Boe, G.H., Danielssen, T \& Finne P.M. Production of base metals from complex sulphide concentrates by the ferric chloride route in a small, continuous pilot plant; Elkem-Center, Kristiansand, Norway IMM, Inglaterra. 210-222. 1980.

- Antonio Ballester, Luis Felipe Verdeja y José Sancho. Metalurgia Extractiva Fundamentos. 1era ed. Editorial Síntesis. Madrid 532-540. 2000.

- Hagler Bailly, Inc. Buenas prácticas de Manufactura en la extracción y el procesamiento de Metales Noferrosos; EP3 Auspiciado por la Agencia Para el Desarrollo internacional de los EE.UU (USAID). 41-44. 1998.

- Morizot, G. Volatilization chloridization with calcium chloride of complex sulphide minerals and concentrates; IMM, Inglaterra. 124-126. 1980.

- Sherman, M. And Strickland L. Dissolution of lead sulfide ores in acid chloride solutions; AIME Transactions VOL. 209 EE.UU. 192-198. 1957.

- Tolley W. And J. Stauter. The recovery of lead from sulfide concentrates using a chlorination, brine leaching and electrolysis process; Report UOP. INC. Illinois. Selected Hydrometallurgical Systems; Martin C. Kuhn, Editor; SME-AIME; New York. 432-436. 1981.

- Guerreros Meza Manuel Cementación de plomo con hierro en soluciones cloruradas, Ciuf - 2005 Pontificia Universidad católica del Perú, proyecto Metalurgia consejo interuniversitario de la comunidad francófona de Bélgica. 2005

○ http://www.pucp.edu.pe/departamento/ingenieria/metal urgia/ciuf/investiga.html

- Guerreros Meza Manuel. Aplicación de la cinética electroquímica al estudio de la cementación del plomo con acero en soluciones cloruradas IV Congreso Internacional de Metalurgia de Transformación http://www.figmm.uni.edu.pe/Publicaciones/lV\%20 Congreso $\% 20$ Internacional $\% 20$ de $\% 20$ Metalurgia $\%$ 202008\%200SCMGMtema.pdf. 2008. 